\title{
Serum Vascular Endothelial Growth Factor and Vascular Endothelial Growth Factor Receptor-1 Levels in Patients With Fibromyalgia Syndrome
}

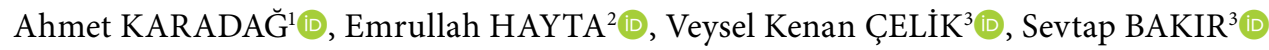 \\ ${ }^{1}$ Department of Physical Medicine and Rehabilitation, Cumhuriyet University School of Medicine, Sivas, Turkey \\ ${ }^{2}$ Department of Physical Medicine and Rehabilitation, Acıbadem Hospital, Istanbul, Turkey \\ ${ }^{3}$ Department of Biochemistry, Cumhuriyet University School of Medicine, Sivas, Turkey
}

\begin{abstract}
Objectives: This study aims to compare the serum vascular endothelial growth factor (VEGF) and vascular endothelial growth factor receptor-1 (VEGFR-1) levels between patients with fibromyalgia syndrome (FMS) and healthy controls.

Patients and methods: The study included 40 female patients (mean age $39.9 \pm 10.2$ years; range, 22 to 52 years) diagnosed with primary FMS according to the American College of Rheumatology criteria (1990) and 40 healthy female volunteers (mean age $40.9 \pm 8.3$ years; range, 25 to 53 years). The sociodemographic data of both groups were recorded. The disease duration and the number of tender points were recorded for patients with FMS, and venous blood samples were collected from the two groups for the measurement of serum VEGF and VEGFR-1 levels.

Results: The FMS and control groups were comparable in terms of age and body mass index ( $p>0.05$ ). A comparison of the serum VEGF levels of the FMS and control groups revealed a statistically insignificant difference ( $p>0.05)$, while a comparison of the serum VEGF-1 levels of the FMS and control groups revealed a statistically significant difference $(p<0.05)$.

Conclusion: Serum VEGFR-1 levels were higher in patients with FMS, while the serum VEGF levels of the FMS patients did not differ from those of the healthy controls.

Keywords: Fibromyalgia syndrome, vascular endothelial growth factor, vascular endothelial growth factor receptor-1.
\end{abstract}

Fibromyalgia syndrome (FMS) is a clinical condition characterized by chronic widespread pain and tender points at specific localized anatomical sites, fatigue, sleep disturbance, cognitive dysfunction and depressive episodes. ${ }^{1,2}$ Previous clinical studies have suggested that genetic, environmental and immunological factors, and peripheral and central mechanisms could play a role in the etiology of FMS, the pathology of which remains unknown. ${ }^{3,4}$ Previous clinical studies have demonstrated vasoconstriction at the tender points of patients with FMS, impairment in microvascular circulation and an associated decrease in blood flow. ${ }^{5,6}$ The impairment of microvascular circulation in the muscles of patients with FMS reduces aerobic capacity, thus affecting angiogenesis at the relevant site..$^{5,7}$

Vascular endothelial growth factor (VEGF) plays an important role in the growth of blood vessels, prevention of endothelial damage and regulation of microvascular circulation, ${ }^{8}$ while hypoxia in particular is known to increase VEGF activity and thereby induce angiogenesis. ${ }^{9}$ VEGF binds to and

Received: October 25, 2018 Accepted: February 10, 2019 Published online: April 22, 2019

Correspondence: Ahmet Karadağ, MD. Cumhuriyet Üniversitesi Tıp Fakültesi Fiziksel Tıp ve Rehabilitasyon Anabilim Dalı, 58140 Sivas, Turkey. Tel: +90 506 - 5335456 e-mail:dr_ahmetkaradag@hotmail.com 
activates two tyrosine kinase receptors-VEGF receptor-1 (VEGFR-1) and VEGFR-2, although VEGFR-1 has a ten-fold higher affinity to VEGF.10 On the other hand, VEGFR-1 is known to be a negative regulator of angiogenesis, while elevated levels of VEGFR-1 result in pathological angiogenesis. ${ }^{11,12}$ The authors consider that impairment in the regulation of angiogenesis may actually be a cause of the impairment demonstrated in microvascular circulation. To our knowledge, there have been only two studies in the literature evaluating the relationship between FMS and VEGF, although evaluating the VEGF level alone may not provide sufficient understanding of the regulation of angiogenesis. In this respect, an evaluation of the VEGF-VEGFR system as a whole may be more beneficial in gaining an understanding of angiogenesis regulation. To our knowledge, previous clinical studies have failed to evaluate VEGFR-1 levels. Therefore, in this study, we aimed to compare the serum VEGF and VEGFR-1 levels between patients with FMS and healthy controls.

\section{PATIENTS AND METHODS}

Forty pre-menopausal patients (mean age $39.9 \pm 10.2$ years; range, 22 to 52 years) diagnosed with FMS criteria according to the American College of Rheumatology criteria (1990)13 and 40 healthy pre-menopausal volunteers (mean age $40.9 \pm 8.3$ years; range, 25 to 53 years) were included in this study conducted at Cumhuriyet University School of Medicine between February 2018 and August 2018. Patients with any cardiovascular, endocrine or hematological diseases that could affect VEGF and VEGFR-1 levels; patients with an acute or chronic infection, inflammatory rheumatic disease or malignancy; patients with lung disease, such as chronic obstructive pulmonary disease or asthma; patients with an impairment in liver or kidney functions; pregnant and lactating females; patients receiving antilipidemic, antioxidant or anti-coagulant drugs; or those using tobacco products or alcohol were excluded. The study protocol was approved by the Cumhuriyet University School of Medicine Ethics Committee. A written informed consent was obtained from each participant. The study was conducted in accordance with the principles of the Declaration of Helsinki.

The sociodemographic data (height, weight, age) of both groups were recorded, and the disease duration and the number of tender points were recorded for the patients with FMS. Venous blood samples were collected into 3-4 mL biochemistry tubes and centrifuged at $+4^{\circ} \mathrm{C}$ and $3000 \mathrm{rpm}$ for five minutes. The sera was stored at $-30^{\circ} \mathrm{C}$ for the measurement of serum VEGF and VEGFR-1 levels. Human VEGF and VEGFR-1 levels were measured with enzyme-linked immunosorbent assay kits (Boster Biological Technology, Pleasanton CA, USA) according to instructions of the manufacturer.

\section{Statistical analysis}

All data analyses were carried out using the IBM SPSS version 22.0 software (IBM Corp., Armonk, NY, USA). Continuous data were expressed as the mean \pm standard deviation. The normal distribution of the data was analyzed using Kolmogorov-Smirnov tests. Student's t-test and a Pearson correlation test were applied when the parametric test assumptions were met. A Mann-Whitney U test was used when the parametric test assumptions could not be met. A $p$ value $<0.05$ was accepted as statistically

Table 1. Sociodemographic data of study groups, and disease duration and number of tender points in fibromyalgia syndrome group

\begin{tabular}{|c|c|c|c|}
\hline & Fibromyalgia syndrome group $(\mathrm{n}=40)$ & Control group $(\mathrm{n}=40)$ & \\
\hline & Mean \pm SD & Mean \pm SD & *p \\
\hline Age (year) & $39.9 \pm 10.2$ & $40.9 \pm 8.3$ & 0.634 \\
\hline Body mass index $\left(\mathrm{kg} / \mathrm{m}^{2}\right)$ & $28.9 \pm 5.0$ & $29.4 \pm 5.5$ & 0.693 \\
\hline Disease duration (month) & $42.1 \pm 27.6$ & & \\
\hline Tender points & $13.5 \pm 1.7$ & & \\
\hline
\end{tabular}


significant. For an $\alpha$ value of 0.05 , a $\beta$ value of 0.10 , and a $1-\beta$ value of $0.90,40$ subjects were included in the FMS group and 40 subjects in the control group, and the power of the test was 0.9091 .

\section{RESULTS}

There were no significant differences between the FMS and control groups in terms of age or BMI values $(p>0.05)$. The sociodemographic characteristics of the groups and disease duration and number of tender points in patients with FMS are presented in Table 1 . The difference between the FMS and control groups was not statistically significant in a comparison of the serum VEGF values $(p>0.05)$ (Figure 1). When the FMS and control groups were compared in terms of serum VEGFR-1 levels, the difference between the

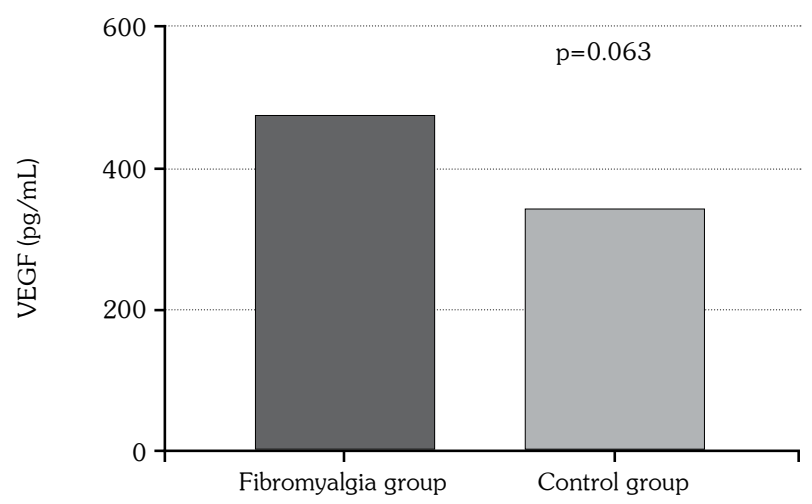

Figure 1. Serum VEGF levels of study groups. VEGF: Vascular endothelial growth factor.

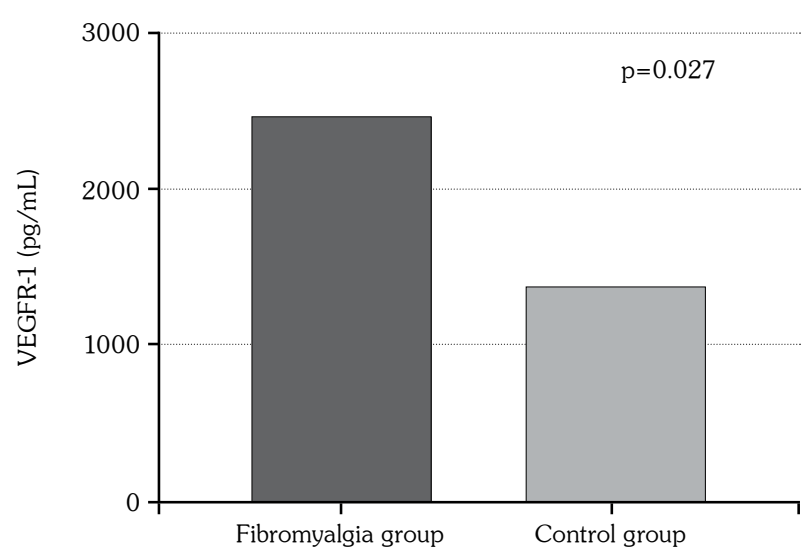

Figure 2. Serum VEGFR-1 levels of study groups. VEGFR-1: Vascular endothelial growth factor receptor-1. two groups was statistically significant $(p<0.05)$ (Figure 2). There was no significant correlation between the serum VEGF and VEGFR-1 levels and disease duration of patients with FMS ( $p>0.05$ ), although a statistically significant positive correlation was noted between serum VEGF and VEGFR-1 levels and the number of tender points in patients with FMS $(p<0.05)$.

\section{DISCUSSION}

In the present study, the serum VEGF levels of patients with FMS were similar to those of healthy individuals, and similar findings have been previously reported in the literature. ${ }^{14}$ On the other hand, patients with FMS had higher serum VEGFR-1 levels than the healthy controls. Furthermore, a significant relationship was identified between the serum VEGF and VEGFR-1 levels of patients with FMS and the number of tender points. In addition, no significant relationship was noted between the serum VEGF and VEGFR-1 levels of patients with FMS and disease duration. To our knowledge, the present study is the first in the literature to report such results.

Vascular endothelial growth factor is a survival factor for endothelial cells, and its expression is impaired in various pathological conditions, such as tumors, diabetic retinopathy, polycystic ovarian syndrome and antiphospholipid antibody syndrome. ${ }^{15-17}$ Furthermore, clinical studies have demonstrated higher VEGF levels accompanying some inflammatory rheumatic diseases. Harada et al. ${ }^{18}$ identified higher VEGF levels in patients with rheumatoid arthritis (RA), and there have been various clinical studies conducted on patients with Behçet's disease (BD) and systemic lupus erythematosus showing elevated serum VEGF levels. ${ }^{19,20}$ There are a limited number of studies in the literature evaluating the relationship between FMS and VEGF. Blanco et al. ${ }^{21}$ found lower serum VEGF levels in patients with FMS than in the normal population, while in another clinical study, serum VEGF levels in patients with FMS were no different to those of the healthy controls. ${ }^{14}$ Similarly, the present study identified no difference in the serum VEGF levels of patients with FMS to those of the healthy controls. 
Vascular endothelial growth factor receptor-1 has low tyrosine kinase activity, and so is thought to play a negative role in angiogenesis. ${ }^{22,23}$ High VEGFR-1 levels have been demonstrated in some inflammatory rheumatic diseases that cause a damage in the vascular system. High VEGFR-1 levels are considered to induce the functioning and release of the macrophages that play a role in vasculitis and angiopathy. ${ }^{24-26}$ In one clinical study, high serum VEGFR-1 levels were identified in patients with RA, ${ }^{12}$ while in a study by Sertoglu et al.,11 serum VEGFR-1 levels were shown to be higher in patients with $\mathrm{BD}$ than in healthy controls, and the same study also showed higher serum VEGFR-1 levels among patients with BD with vascular involvement than those without vascular involvement. ${ }^{11}$ The present study found higher VEGFR-1 levels in patients with FMS than in the healthy controls.

The limitations of the present study include its small sample size, the lack of histopathological examinations, the lack of male patients with FMS, the evaluation of patients with FMS according to the recent classification criteria, no evaluations of pain or quality of life parameters in FMS, and not having measured the other hormones or cytokines that play a role in angiogenesis.

In conclusion, the present study found normal serum VEGF levels and higher serum VEGFR-1 levels in patients with FMS. Furthermore, no relationship was found between the serum VEGF and VEGFR-1 levels of patients with FMS and disease duration. Nonetheless, further comprehensive clinical studies are required evaluating serum VEGF and VEGFR-1 in patients with FMS.

\section{Declaration of conflicting interests}

The authors declared no conflicts of interest with respect to the authorship and/or publication of this article.

\section{Funding}

The authors received no financial support for the research and/or authorship of this article.

\section{REFERENCES}

1. Theoharides TC, Tsilioni I, Arbetman L, Panagiotidou S, Stewart JM, Gleason RM, et al. Fibromyalgia syndrome in need of effective treatments.
J Pharmacol Exp Ther 2015;355:255-63.

2. Adler GK, Manfredsdottir VF, Creskoff KW. Neuroendocrine abnormalities in fibromyalgia. Curr Pain Headache Rep 2002;6:289-98.

3. Dadabhoy D, Clauw DJ. Therapy Insight: fibromyalgia-a different type of pain needing a different type of treatment. Nat Clin Pract Rheumatol 2006;2:364-72.

4. Albrecht PJ, Rice FL. Fibromyalgia syndrome pathology and environmental influences on afflictions with medically unexplained symptoms. Rev Environ Health 2016;31:281-94.

5. Jeschonneck M, Grohmann G, Hein G, Sprott H. Abnormal microcirculation and temperature in skin above tender points in patients with fibromyalgia. Rheumatology (Oxford) 2000;39:917-21.

6. Morf S, Amann-Vesti B, Forster A, Franzeck UK, Koppensteiner R, Uebelhart D, et al. Microcirculation abnormalities in patients with fibromyalgia - measured by capillary microscopy and laser fluxmetry. Arthritis Res Ther 2005;7:209-16.

7. Bikfalvi A. Recent developments in the inhibition of angiogenesis: examples from studies on platelet factor-4 and the VEGF/VEGFR system. Biochem Pharmacol 2004;68:1017-21.

8. Hoeben A, Landuyt B, Highley MS, Wildiers H, Van Oosterom AT, De Bruijn EA. Vascular endothelial growth factor and angiogenesis. Pharmacol Rev 2004;56:549-80.

9. Tong JP, Yao YF. Contribution of VEGF and PEDF to choroidal angiogenesis: a need for balanced expressions. Clin Biochem 2006;39:267-76.

10. Park K, Amano H, Ito Y, Kashiwagi S, Yamazaki Y, Takeda A, et al. Vascular endothelial growth factor receptor-1 (VEGFR-1) signaling enhances angiogenesis in a surgical sponge model. Biomed Pharmacother 2016;78:140-9.

11. Sertoglu E, Omma A, Yucel C, Colak S, Sandıkc1 SC, Ozgurtas T. The relationship of serum VEGF and sVEGFR-1 levels with vascular involvement in patients with Behçet's disease. Scand J Clin Lab Invest 2018;78:443-9.

12. Paradowska-Gorycka A, Sowinska A, Pawlik A, Malinowski D, Stypinska B, Haladyj E, et al. FLT-1 gene polymorphisms and protein expression profile in rheumatoid arthritis. PLoS One 2017;12:e0172018.

13. Wolfe F, Smythe HA, Yunus MB, Bennett RM, Bombardier C, Goldenberg DL, et al. The American College of Rheumatology 1990 Criteria for the Classification of Fibromyalgia. Report of the Multicenter Criteria Committee. Arthritis Rheum 1990;33:160-72.

14. Kim SK, Kim KS, Lee YS, Park SH, Choe JY. Arterial stiffness and proinflammatory cytokines in fibromyalgia syndrome. Clin Exp Rheumatol 2010;28:71-7.

15. Williams FM, Parmar K, Hughes GR, Hunt BJ. Systemic endothelial cell markers in primary antiphospholipid syndrome. Thromb Haemost 2000;84:742-6. 
16. Tulandi T, Saleh A, Morris D, Jacobs HS, Payne NN, Tan SL. Effects of laparoscopic ovarian drilling on serum vascular endothelial growth factor and on insulin responses to the oral glucose tolerance test in women with polycystic ovary syndrome. Fertil Steril 2000;74:585-8.

17. Dvorak HF, Brown LF, Detmar M, Dvorak AM. Vascular permeability factor/vascular endothelial growth factor, microvascular hyperpermeability, and angiogenesis. Am J Pathol 1995;146:1029-39.

18. Harada M, Mitsuyama K, Yoshida H, Sakisaka S, Taniguchi E, Kawaguchi T, et al. Vascular endothelial growth factor in patients with rheumatoid arthritis. Scand J Rheumatol 1998;27:377-80.

19. Oztürk MA, Unverdi S, Oktar SO, Bukan N, Gülbahar O, Ureten K, et al. Vascular endothelial growth factor and carotid intima-media thickness in patients with Behçet's disease. Clin Rheumatol 2008;27:961-6.

20. Heshmat NM, El-Kerdany TH. Serum levels of vascular endothelial growth factor in children and adolescents with systemic lupus erythematosus. Pediatr Allergy Immunol 2007; 18:346-53.

21. Blanco I, Janciauskiene S, Nita I, Fernández-Bustillo E, Cárcaba V, Gallo C, et al. Low plasma levels of monocyte chemoattractant protein-1 (MCP-1), tumor necrosis factor-alpha (TNFalpha), and vascular endothelial growth factor (VEGF) in patients with alpha1-antitrypsin deficiency-related fibromyalgia. Clin Rheumatol 2010;29:189-97.

22. Fong GH, Rossant J, Gertsenstein M, Breitman ML. Role of the Flt-1 receptor tyrosine kinase in regulating the assembly of vascular endothelium. Nature 1995;376:66-70.

23. Hiratsuka S, Minowa O, Kuno J, Noda T, Shibuya M. Flt-1 lacking the tyrosine kinase domain is sufficient for normal development and angiogenesis in mice. Proc Natl Acad Sci U S A 1998;95:9349-54.

24. Luttun A, Tjwa M, Moons L, Wu Y, Angelillo-Scherrer A, Liao F, et al. Revascularization of ischemic tissues by PlGF treatment, and inhibition of tumor angiogenesis, arthritis and atherosclerosis by anti-Flt1. Nat Med 2002;8:831-40.

25. De Bandt $\mathrm{M}$, Ben Mahdi $\mathrm{MH}$, Ollivier V, Grossin M, Dupuis M, Gaudry M, et al. Blockade of vascular endothelial growth factor receptor I (VEGF-RI), but not VEGF-RII, suppresses joint destruction in the $\mathrm{K} / \mathrm{BxN}$ model of rheumatoid arthritis. $\mathrm{J}$ Immunol 2003;171:4853-9.

26. Shibuya M. Vascular endothelial growth factor receptor-1 (VEGFR-1/Flt-1): a dual regulator for angiogenesis. Angiogenesis 2006;9:225-30. 